\title{
Галина Георгиева
}

\section{Из Acmepoud 35111}

Пиеса в четири акта с пролог и епилог*

\section{ДЕЙСТВАЩИ ЛИЦА}

\section{Мъж 1}

МъЖ 2

ГЕОРГИ ЕФРОН, МУР, СИН

АРИАДНА ЕФРОН, АЛЯ, дъщеря

СЕРГЕЙ ЕФРОН, СЪПрУح

ГЛАС 3, женСКИ

ГЛАС 4, мъжКИ

\section{ПРОЛОГ}

Преди вдигането на завесата се чува запис от разговор между четирима участници - трима мъже и една жена.

ГЛАС 1. Мисля да напиша поема за синтетичния каучук.

ГЛАС 2. Може ли?

ГЛАС 1. Защо да не може? Всичко е тема!

ГЛАС 2. От сърце ли ще е?

ГЛАС 1. От сърце... и от душа! Отвътре!

ГлАС 2. За какво ще служи?

ГЛАС 1. Днес синтетичният каучук е важна сплав на нашия прогрес.

ГЛАС 2. Сърцето на прогреса! Значи е нужно!

ГЛАС 3 (женски). Синтетичният каучук не се нуждае от поеми, за него има заводи! От поезия се нуждаят само нещата, от които не се нуждае никой. Тя е най-бедното място на цялата земя. И тя е място свято.

ГЛАС 2. Коя е тази?

ГлАС 4. Марина Цветаева. Поетеса.

ГЛАС 1. Наша ли е?

ГЛАС 4 (тръгва да отговаря, но се спира).

ГЛАС 1. Откъде е?

ГЛАС 4. От предела. От най-горния регистър. От края на последната октава.

глАС 2. Откъде?

* В пиесата са използвани факти от живота на руската поетеса Марина Цветаева и нейното семейство. 
Галина Д. Георгиева завършва кинорежисура в НБУ. Преди това е завършила руска филология в СУ „Св. Климент Охридски“ с докторат по руска литература на ХХ век. Автор е на книгата „Авангард и соцреализъм. Проблемът за лириката в Русия през периода 1917-1934“. Участва в редица международни работилници по сценарно писане и режисура. Неин сценарий („Репетиции“) печели първа награда на конкурса на Ниси Маса за най-добър сценарий в Европа.
Автор е на документалния филм „Булеварден роман" (селектиран на София филм фест), на научнопопулярния „БАН 145 години“ (излъчен по БНТ), на няколко игрални късометражни филма. Последният й филм „Френско кино“ е подкрепен от НФЦ. Работила е като асистент-режисьор във филмови продукции на $\mathrm{Cm}$. Командарев, $P$. Спасов, К. Бонев. Автор на критически материали в културната периодика. Главен асистент в Института за литература, БАН.

ГЛАС 4. Тръгна от предела и стигна... по-далеч от всички ни.

ГЛАС 2. Значи може да е наша.

ГЛАС 1. В ямб ли пише?

ГЛАС 4. В амфибрахий, понякога в дактил.

ГЛАС 1. А вие кой сте?

ГЛАС 4. Неин наследник.

ГЛАС 2. По чия линия?

ГЛАС 4. По занятие... Аз съм Онзи, който пуши в тъмното и вдишва гнилия въздух на отлива. Аз съм Онази, която написа. Ще умра без да кажа. Аз бях! Аз съм крайната черта на времето, пределът на хоризонта!

Завесата се вдига.

I АКТ. 10-И ОТДЕЛ (ОТЧЕТНО-АРХИВЕН)

МъЖ 2 е качен на стълба, рови се в стар каталог. Облечен е семпло, като в облеклото му ярко се открояват две червени нашивки. МъЖ 1 е седнал зад груба маса - пред него е разгърната папка - Инвентарната книга, слуша партньора си и отбелязва в папката. МъЖ 1 е облечен по същия начин, но има три червени нашивки. На видно място в помещението стои надпис. 10-и ОТЧЕТНО-АРХИВЕН ОТДЕЛ.

Мъж 2 (чете от картонче в каталога). С „Макаров”, февруари месец. Оставил писмо и дългове.

МъЖ 1. Номер?

МъЖ 2. 56.

Мъж 1 (отбелязва в папката). Номер 56.

Мъж 2. С винтовка... с пневматична винтовка!?

Мъж 1. Сигурно е служил.

Мъж 2. Сигурно. Ноември. Оставил... къща, нива и две писма. Номер 57.

Мъж 1. 57... Описан.

МъЖ 2. С „Берета 92”, януари. Оставил... жена и три кокошки. 58.

Мъж 1. 58... Протокол има ли?

Мъж 2 (вглежда се в картончето). Пише, че има.

МъЖ 1. Предният има ли? 
Мъж 2. Има.

Мъж 1. По-предният?

МъЖ 2. И той.

Мъж 1. Идеално. (Дава знак да продължи.)

Мъж 2. С „Валтер ПП”... ноември. Оставил... нищо не е оставил. 59.

Мъж 1 (отмята). 60?

Мъж 2. Няма 60. Дотука. (Преглежда набързо картончета в иялото чекмедже.) Така, така, така... Обща бройка - 14.

Мъж 1 (сверява с папката). 14 огнестрелни! Нататък!

Мъж 2 (отваря чекмедже, на което пише „Отрови”). Отрови. С отрова за мишки, март. Оставил самовар, крава и болен баща.

Мъж 1 (отваря нова папка). Номер?

Мъж 2. Води се 17.

МъЖ 1. Правилно се води.

Мъж 2. 18... с цианид...

МъЖ 1. Дай направо бройка!

Мъж 2. Чакай, чакай... тука има един, дето се е хвърлил под влака.

Мъж 1. Отива при други!

Мъж 2 (вади му картончето). Отива при други... Бройка на отровите искаш ли? (МъЖ 1 му кима.) 21. Без тоя с влака.

Мъж 1. И при мен са 21. (Пауза. 7 удавници, 14 с огнестрелни, 21 с отрови. (Доволен.) Дай Други!

Мъж 2 (вече е отворил каталога с Други). Номер 19... прерязани вени. Класика! Протоколиран! Номер 20... с чук... Кой се самоубива с чук бе, човек!

Мъж 1 (прекъсва го). При мен са 28.

МъЖ 2. Кои?

Мъж 1. Другите.

Мъж 2 (брои). При мен са 27.

МъЖ 1. Дай пак!

МъЖ 2 (брои). 27.

МъЖ 1. Кой ти е последният?

Мъж 2. Някой си с У.

МъЖ 1 (гледа в книгата). Успенски.

Мъж 2. Да. (Сеща се.) Добре де, нали извадихме от отровите оня с влака?! Слагаме го тука и готово. Стават 28.

Мъж 1. Не може! При мен след У има с Ц.

МъЖ 2. С Ц?

Мъж 1. ъхъ... някаква Цветаева.

МъЖ 2 (пак преглежда каталога). Как й е първото име?

Мъж 1. Марина.

Мъж 2. Няма такава.

МъЖ 1. Това не е добре.

Мъж 2 ще й направим картонче.

Мъж 1. Някъде има грешка.

МъЖ 2. Или... ще я изтрием! От книгата (прави жест), цък - изтрита! 
Мъж 1. Има грешка по процедура.

Мъж 2. Тогава картонче.

Мъж 1. Има разминаване между Инвентарната книга и каталога. Грешка по процедурата на вписването.

Мъж 2. Но не е наша.

МъЖ 1. Ще я направят наша. Предишните ги няма. Изпратиха ги на Север.

Мъж 2. Опааа.

Мъж 1. Сега разбираш ли?

Мъж 2. Значи и нас могат да изпратят на Север?

Мъж 1. Може да се допусне. Ако не... поправим грешката.

Мъж 2. А може и да е нарочно. За да ни гледат сеира.

МъЖ 1. Чак толкова. Аз съм с три нашивки.

Мъж 2. Вярно. Скоро и аз ще стана с три.

Мъж 1. По-лесно е да я изтрием от списъка.

Мъж 2. Или да й направим картонче. Мисля, че картонче е по-лесно. Правим й картонче, ти го правиш - (посочва го) с три нашивки - мушваме го, след У и си ходим! Чиста работа. (Тихо.) Тайна работа...

Мъж 1. Няма такава работа! Тука всичко е с протокол - черно на бяло.

Мъж 2. Пише ли кога е (шепне) извършено деянието?

Мъж 1. 31 август 1941 година, в Елабуга.

Мъж 2. Къде е Елабуга?

Двамата внезапно се сещат за нещо, което ги изпълва с възмущение.

Мъж 1. Не може! Не, не, не, не може!

Мъж 2 (тихо). Ами че това е... преди!

МъЖ 1. Тия хора не четат ли вестници?! (Изважда от джоба си сгънат на четири лист от вестник, подава му го.) Чети!

Мъж 2 (взима вестника). Според новоприетия Декрет за лятната физическа култура на гражданите (ЕЛФЕКА на гражданите) между 1 май и 1 септември никой не може да извършва каквото и да било посегателство над себе си. Деяния, чиято крайна и предумишлена цел е самоубийство, могат да се извършват в регламентираното за това време, тоест в есенно-зимния сезон.

Мъж 1. Лятото не може!

Мъж 2. Не е... удобно.

Мъж 1. Още един ден да бе изчакала поне! (Поглежда пак в книгата, изумява се още повече.) Ами тука е действано с въже.

Мъж 2. Как така с въже?

Мъж 1. Така. Обесила се е!

Мъж 2. И това не може! Забранено е! (Пак чете от вестника.) Деянието може да се извършва с отрова, с огнестрелно оръжие, чрез самозапалване, чрез удавяне, чрез телесна щета - прерязване на вени, удар с брадва и други (други е подчертано), но не и с въже, тоест чрез обесване.

Мъж 1. Да беше се гръмнала!

Мъж 2. Да беше! А защо не може с въже?

Мъж 1. Ти административния правилник чел ли си? (Показва му го, окачен на стената.) С въже работим само ние, понякога и с тел (прави жест на удушаване). 
По традиция! И по избор! Само достойните... са достойни за въже.

Мъж 2. А онзи... Есенин?

Мъж 1. Той е отпреди Декрета.

Мъж 2. А, да. А може и да е бил достоен?!

Мъж 1. Донеси й папката!

Мъж 2. Не е ли прибързано?

МъЖ 1. Нарушени са две забрани от Декрета, известен като „ЕЛФЕКА на гражданите”. деянието е извършено извън сезона, деянието е извършено с въже.

Мъж 2. Бих закусил.

МъЖ 1. Какво би?

Мъж 2. Закусил?

Мъж 1. С хайвер едва ли не?

Мъж 2. И каша ми стига. Овесена каша с чай.

Мъж 1. Първо папката!

Мъж 2 се подчинява без желание, слиза от стълбата, рови в няколко шкафа, намира папката на Цветаева. Отварят я - на пьрвия лист пише. Марина Цветаева. ПОЕТ, ПРЕВОДАЧ. Следват множество празни листове.

Мъж 1. Марина Цветаева. Поет. Зачеркнато. Преводач. Не е зле, а? Зачеркнат поет! (Прави знак, че ще я изтрие от книгата.)

Мъж 2 (вижда с дребни букви нещо, чете). Оставила. две деца, мъж, накити, тетрадки и три писма. (Замисля се.) Но има и основание за картонче! (Оглежда се.) Могат да ни сервират поне чай!

МъЖ 1. Кой да ни сервира?

МъЖ 2. Някой. Явно ще пишем протокол?!

Мъж 1. Ще свършим бързо.

Мъж 2 Аз бързо го пия. А и нали си с три нашивки?!

Мъж 1 (с променен тон и вид). Викай ги един по един! Ще разпитваме!

Мъж 2. Кого ще разпитваме?

Мъж 1. Когото е оставила! Две деца, мъж...

Мъж 2. Дали са живи?

Мъж 1. Който е останал. Намери ми писмата и тетрадките!

II АКТ - РАЗПИТ 1 - ГЕОРГИ ЕФРОН, МУР

На сцената е тъмно. Двамата мъже светят с фенерче и четат измачкано писмо.

Мъж 1. Не ме погребвайте жива! Проверете добре!

Мъж 2 сърба чай. Глухо жужене се носи из въздуха. В този момент електрическото таблото щраква и лампите светват, жуженето изчезва.

Мъж 2. Дойде! Токът дойде!

Мъж 1 (вижда Мур). Синът... заповядайте... дойде синът! (Мушва писмото в джоба 
си.) Приготвили сме ви бонбони. Заповядайте!

МъЖ 1 минава край масата, взима бурканче с бонбони, опаковани в различни цветни картинки, подава му ги, но Мур отказва, мъжът го приканва.

Мъж 1. Последните от тази поредица.

Мъж 2. Догодина ще има друга - с Мечока Миша Късокраков!

МУР. И трите писма ли са при вас?

Мъж 1. Чакайте, чакайте! Дайте по протокола!

Мъж 2. По протокола е най-добре.

Двамата се настаняват, придават си важност, Мур също сяда.

МъЖ 1. Име?

МУР. Георги Ефрон, Мур.

Мъж 2 (изкарва го на песен). Мурка, ты мой Мурьоночек, Мурка, ты мой котьоночек.

Мъж 1. Доста буржоазно.

МУР. Идва от Хофман. От котарака Мур на Хофман. (Двамата не реагират.) Немски писател, романтик.

Мъж 2. Още по-буржоазно.

Мъж 1. Кажете ми, Георги... Мур, какви бяха отношенията ви с лицето Марина Ивановна Цветаева?

МУР. Вижте, аз съм мъж с приятен и мек нрав... (Оправя ръкава на ризата си.)

МъЖ 1 (подава му кутията с бонбони). От поредицата „Московчани”! (Този път Мур си взима.)

МъЖ 2. Като покойната! Московчанка, нали, майка ви е московчанка?!

МуР (оставя бонбона). Вижте, случаят е стар.

Мъж 2. Може и да е стар, но ние правим протокол.

Мъж 1. Потвърждавате ли, че сте последният, видял и разговарял с покойната приживе?

МУР. Не знаех, че с покойните може да се разговаря и иначе, НЕприживе. Последният съм, да. Доколкото с Марина Ивановна въобще можеше да се разговаря. (Пауза.)

Особено накрая.

Мъж 1. Накрая. Казвате го сякаш краят е бил...

Мъж 2. Предопределен.

Мъж 1. Целеположен.

МъЖ 2. Предвещан! (Онзи го поглежда лошо.) Це-ле-по-ло-жен (Записва в протокола, подава кутията с бонбони на Мур.) Ето тука има и други - с бяла мечка, Миша на

Север.

МУР. Откъде имате писмата й?

Мъж 1. Откъдето имаме и бонбоните.

Мъж 2. Ние сме архивен отдел. Имаме архив.

Мъж 1. Кажете за края!

Мур мълчи.

МъЖ 2. Били ли сте на Север?

МУР. В Париж съм бил.

Мъж 2 (подава му бонбон). С Миша на Север - вземете си!

МУР. „Остава ми само да се обеся“, ей така говореше. Всеки ден го говореше, даже го беше записала в една тетрадка... 
МъЖ 1. Значи признавате, че деянието е било планирано.

МУР. Никой не се самоубива спонтанно.

Мъж 2 (диктува си и записва). Целепоставено нарушение...

Мъж 1 (поправя го). Целеположено!

Мъж 2. ...нарушение на забраната от Декрета... (Пауза.) Можела е да изчака един ден! От първи септември вече може. „ЛЕФЕКА на гражданите” беше пуснат навсякъде.

МъЖ 1. Подозрително нетърпение за планирано деяние. (Baди едното писмото от джоба си.) А и в писмата пише...

МУР. Вижте, нямам отношение към... деянието. Нито към датата, нито към начина... Марина Ивановна не искаше да се връща в Русия. Знаеше, че това ще я погуби... буквално.

МъЖ 1. Никой не знае какво ще го погуби буквално.

МУР. Поетите знаят. (Спомня си.) Бързам, опитвам се да стигна... но си спомням, че съм забравила нещо, връщам се, търся... търся плоча... Морис Шевалие, любимата ми, с Donnez-moi la main, mam'zelle... Donnez-moi la main, Подайте ми ръка,

госпожице... подайте ми ръка... А параходът е вече далеч - на километри... (Пауза.) Това ми разказа, докато пътувахме от Франция за насам. Сънувала го вечерта, преди да заминем. Да беше се върнала за плочата.

Мъж 2. И да бяхте изпуснали парахода?!

Мъж 1. Да не твърдите, че... ние сме виновни, в смисъл - родината?

МУР. Твърдя... твърдя, че...

МъЖ 1. ...сте станали жертва на лоши обстоятелства?

МУР. Това оправдание никога не ми е било на равнището. Твърдя, че... някои сънища са по-полезни от някои реалности.

Мъж 2. Мъдро! (Към МъЖ 1.) Мъдро ли е?

Мъж 1. Продължете!

МУР. След като бяхме евакуирани от Москва в Елабуга... (Мур най-после си взима бонбон, увит в целофан с маргаритка.)

Мъж 2. Точно така с маргаритка! (Пауза.) Евакуирани заради войната?

МУР. Половин Москва беше евакуирана! С влакове, параходи! Ние бяхме с параход.

... Докато пътувахме, две възторжени дами й обещаха, че ще я уредят на работа в Чистопол - знаят коя е и няма да я оставят. В Чистопол бяха повечето писатели, нас ни свалиха в Елабуга.

МъЖ 1. И?

МУР. В Елабуга нямаше нищо.

МъЖ 2. Построиха аеродрум!

Мъж 1. Как покойната се е сдобила с въжето?

Мур мълчи. МъЖ 1 вади уж небрежно от джоба си и трите писма, после бавно ги прибира обратно.

МУР. Даде й го Борис Леонидович... Пастернак.

Мъж 2 (записва). Пас-тер-нак.

МУР. Борис Леонидович дойде у нас, за да помогне на Марина Ивановна да опакова багажа за заминаването, донесе й едно въже... здраво въже, с което да стегне куфара си. „Това въже всичко ще издържи, ако искаш, можеш и да се обесиш на него”, така й каза. На шега й го каза. 
Мъж 1. Някои шеги са по-добри от други шеги.

МУР. Пастернак винаги е бил много непрактичен човек.

Мъж 2. Да го пишем ли виновен?

Мъж 1. Кой?

Мъж 2. Този, Пастернак.

Мъж 1. Сложи го под въпрос. От кого е намерено тялото?

МУР. От хазяйката. Анастасия Ивановна.

Мъж 1. А вие къде бяхте по време на деянието?

МУР. Какво ми намеквате? Марина Ивановна не обичаше водата, отровата намираше за несигурна, а пушка нямаше.

Мъж 1. Къде бяхте?

МУР. На военно обучение. Извикаха ме.

Мъж 1. И? Обучихте се и се прибрахте. Какво видяхте? В квартирата ви в Елабуга?

МУР. Миришеше на лук.

Мъж 2. Някой е готвил?

МУР. В Елабуга винаги мирише на... лук и тор... Тялото лежеше на дивана. Въжето беше на масата. Марина Ивановна беше със своята престилка с голям джоб... може и да е готвила.

Мъж 1. Дайте да обобщим - казахте, че лицето е планирало своето деяние отдавна... сега описвате лицето като домакиня с джоб...

Мъж 2 (допълва). Домакиня в престилка с голям джоб!

Мъж 1. ...която преди да си тури въжето, решава да ви сготви!?

Мур. Може и да е действала импулсивно.

Мъж 2. Опитахте ли манджата?

MУP. Excusez moi, messieurs, но пак да кажа. не разбирам това вълнение относно Марина Цветаева сега!

Мъж 2. Не е въпрос на вълнение, а на протокол.

Мъж 1. Кога слязохте в Елабуга?

МУР. На 18 август. След няколко дни Марина Ивановна замина за Чистопол.

Мъж 2 (вписва в протокола). Деянието е извършено на тринайсетия ден след пристигането в Елабуга. И?

МУР. В Чистопол й казали, че ще откриват столова към Литфонда. И Марина Ивановна подала молба. (Вади от джоба си малка бележка, чете:) „До съвета на Литфонда. Моля да ме приемете на работа в качеството на съдомиячка в откриващата се столова на Литфонда. 26 август 1941 година. Марина Цветаева". (Дълга пауза.) За протокола. Марина Цветаева беше автор на няколко книги с поезия, първата излиза през 1910 година, когато никой в тази стая още не е бил роден, свободно владееше немски, чешки и английски, френският й беше като роден. Превеждаше Бодлер - френски поет, беше близка с Рилке - немски поет, в сърцето на Париж четеше лекции за Александър Сергеевич Пушкин, руски поет, за Блок и Маяковски. Последната й молба беше да я вземат на работа като миячка на чинии в столовата на Литфонда на Чистопол.

Мъж 2. Маяковски е с картонче.

Мур го гледа неразбиращо.

Мъж 2. Маяковски е при нас, с картонче, при огнестрелните. 